\title{
Epistemic Injustice and the Attention Economy
}

\author{
Leonie Smith ${ }^{1}$ (1) - Alfred Archer $^{2}$ (1)
}

Published online: 5 September 2020

(C) The Author(s) 2020

\begin{abstract}
In recent years, a significant body of literature has emerged on the subject of epistemic injustice: wrongful harms done to people in their capacities as knowers (Fricker 2007). Up to now this literature has ignored the role that attention has to play in epistemic injustice. This paper makes a first step towards addressing this gap. We argue that giving someone less attention than they are due, which we call an epistemic attention deficit, is a distinct form of epistemic injustice. We begin by outlining what we mean by epistemic attention deficits, which we understand as a failure to pay someone the attention they are due in their role as an epistemic agent. We argue that these deficits constitute epistemic injustices for two reasons. First, they affect someone's ability to influence what others believe. Second, they affect one's ability to influence the shared common ground in which testimonial exchanges take place. We then outline the various ways in which epistemic attention deficits harm those who are subject to them. We argue that epistemic attention deficits are harms in and of themselves because they deprive people of an essential component of epistemic agency. Moreover, epistemic attention deficits reduce an agent's ability to participate in valuable epistemic practices. These two forms of harm have important impacts on educational performance and the distribution of resources. Finally, we argue that epistemic attention deficits both hinder and shape the development of epistemic agency. We finish by exploring some practical implications arising from our discussion.
\end{abstract}

Keywords Attention economy · Education · Epistemic agency $\cdot$ Epistemic attention · Working class $\cdot$ Epistemic injustice

Leonie Smith

L.smith@manchester.ac.uk

1 The University of Manchester (Philosophy), Manchester, UK

2 The Tilburg Centre for Logic, Ethics and Philosophy of Science (TiLPS), Tilburg University, Tilburg, Netherlands 


\section{Introduction}

Teachers focus on middle-class students at the expense of working-class children in the classroom (Calarco 2011, 2014; Reay 2017); the voices of poor people are significantly absent from media reports about poverty (McKendrick et al. 2008); and the works of black women writers are marginalised by an intellectual and educational system that continues to prioritise the voices of privileged white men and women (Collins 2000).

These three quite different examples from the educational and journalistic spheres are all characterised by a marginalised or underprivileged group receiving less epistemic attention than they are due. In this paper, we will argue that this constitutes a distinct and hitherto unexamined form of epistemic injustice.

An epistemic injustice is an injustice done to someone in their capacity as a knower. Miranda Fricker's work to identify this concept (Fricker 2007), and to introduce two particular forms it can take - testimonial and hermeneutical - has prompted a significant body of literature. This literature has sought to develop our understanding of both testimonial (Dotson 2011; Medina 2011) and hermeneutical (Pohlhaus 2012; Crerar 2016) injustice, ${ }^{1}$ to broaden and deepen our understanding of how social structures interact with these forms of injustice (Anderson 2012; Fricker 2012), and to identify other distinctive forms of epistemic harm, such as epistemic appropriation (Davis 2018), epistemic exploitation (Berenstain 2016) and epistemic trespassing (Ballantyne 2019). However, up to now, the specific importance of attention for the issue of epistemic injustice has been largely overlooked. This stands in contrast to the increased focus on the importance of attention in philosophy of mind (Watzl 2017; Wu 2014), political theory (Bueno 2016; Doran 2017) and economics (Lanham 2006; Wu 2017).

This paper seeks to address this gap by investigating the relationship between attention and epistemic injustice. More specifically, we argue that the level of attention one receives can constitute an independent form of epistemic injustice. We begin, in $\S 2$, by arguing that epistemic attention deficits affect someone's ability to influence what others believe and their ability to influence the shared common ground in which testimonial exchanges take place. Then, in $\$ 3$, we outline the various ways in which these deficits harm those who are subject to them, exploring the connection between epistemic attentional deficits and epistemic agency and arguing that deficits both hinder and shape the development of epistemic agency through a range of mechanisms. In $\S 4$, we argue that epistemic attentional deficits cannot be reduced to other forms of epistemic injustice, such as testimonial and hermeneutic injustices. As we explain, however, they do interact with these other forms of epistemic injustice in interesting ways. We finish, in $\S 5$, by exploring some of the practical implications arising from our discussion. $\S 6$ concludes, with a few notes for possible avenues for further inquiry.

\section{Attention, Agenda Setting, and Establishing the Common Ground}

We begin by explaining how we are using the term 'attention'.

\footnotetext{
${ }^{1}$ Including through reconceptualising epistemic injustice in other ways, as, for example, epistemic oppression (Dotson 2011). 


\subsection{Attention and Epistemic Attention Deficits}

A number of (often competing) proposals about what attention is have been put forward by both psychologists and philosophers of mind. These include the claim that attention involves: a system of selection of perceptual information (Broadbent 1958); a process of projecting information to working memory (Prinz 2005, 2011); a system of selection for action (Wu 2014) or a structuring of our consciousness (Watzl 2017). However, for our purposes it is enough to outline some basic and uncontroversial features of attention. We take as our starting point, the following explanation of attention from William James:

Everyone knows what attention is. It is the possession by the mind, in a clear and vivid form, of one out of what seem several simultaneously possible objects or trains of thought. Focalization, concentration of consciousness are of its essence. It implies withdrawal from some things in order to effectively deal with others. (James 1890/1981: 403-4).

This quotation nicely highlights two of three important features of attention that we wish to draw attention to. First, attention is selective or contrastive. It involves focalising or concentrating on some objects in place of others. For example, in order to read a newspaper in a crowded café one must pay attention to the words being read rather than the conversation at the next table. Second, attention involves some degree of voluntary control. We can choose, to some extent, what we give attention to. To return to the previous example: it is to some extent up to us whether we choose to pay attention to the newspaper or our neighbour's conversation.

The third feature of attention that we wish to focus on is that it susceptible to external influence. If the people at the next table begin to shout then we may no longer be able to pay attention to the newspaper. In addition to such incidental features of our environment there will also be features of our environment deliberately designed to capture our attention. The siren on an emergency vehicle, for example, is designed to immediately focus our attention to its presence. Perhaps more objectionably, advertisements are also deliberately designed to capture our attention. Our attention may be drawn to either the siren or the advert even if we don't want it to be.

Moreover, our attention is greatly influenced by the social and cultural context we live in and by the context in which we were raised. As Eviatar Zerubavel (2015: 10) points out, "We are socialized into culturally, subculturally (ideologically, professional), and historically specific norms, conventions, and traditions of attending that actually determine what we come to regard as attention-worthy and what we effectively ignore." 2 Our cultural context may be structured in a way that encourages us to attend to certain things and not others. For example, a consumerist culture may encourage people to pay attention to how wealthy they are in comparison to other people. Similarly, our cultural training may influence how we are able to pay attention. According to several studies in cultural cognition (e.g. Boduroglu et al. 2009; Masuda and Nisbett 2001), for example, there are differences in the ways in which people from East Asian and Western cultures attend to the same object, with East Asians displaying a wider attentional focus and attending more to contextual information than Westerners whose attention tends to be more narrowly focused on salient objects.

We use the term epistemic attention deficit to refer to the unjust scenario in which someone is paid less epistemic attention than they ought to be paid. There are many ways of paying attention to someone. For example, I may pay attention to a loud and aggressive drunk in a similar way to

${ }^{2}$ As Zerubavel (2015: 9) notes, attention will also be influenced by our physiological nature but this point is less relevant for our purposes. 
the way I pay attention to the siren of the emergency vehicle. I am alerted to their presence and do my best to pay attention to where they are heading in order to get out of their way. This way of paying attention to someone is not what we are interested in here. Rather we are interested in the attention paid to people as epistemic agents. That includes the attention paid to people in their role as potential sources of testimony but also their role as people with epistemic capacities that can be acknowledged, developed and celebrated. Epistemic attention deficits are therefore, by definition, always unjust: a deficit occurs when the amount of something falls short of what it ought to be; and the 'something' we have fallen short of is the right kind of epistemic attention. A mere lack of attention, in itself, is not a deficit and a deficit of other forms of attention (such as emotional attention, for example) is not an epistemic attention deficit. ${ }^{3}$

Epistemic attention deficits may occur because of an individual failing to give another person the attention they are due, or they may result from external influence. This influence may be interventionist and deliberate. For example, a newspaper owner could deliberately block their reporters from interviewing asylum-seekers. By doing so they make it harder for the newspaper's readers to attend to asylum-seeker's voices. But it may also be the product of institutional structures and social systems that shape people's attention in ways that discourage people from giving someone or some groups of people the attention they are due. ${ }^{4}$ If we find a deficit in the epistemic attention paid to asylum seekers in the news, for example, individual journalists may bear some responsibility for marginalising certain voices but a great deal of the responsibility may lie with social and institutional systems that make it difficult for journalists (or researchers of any kind) to pay attention to those voices (MacFayden 2018). These structures may not be the result of any conscious design (or at least not one designed to specifically restrict epistemic attention) but nevertheless play a crucial role in determining who receives the epistemic attention they are due.

Note that this definition also leaves open the possibility that a person may experience an excess of attention in some general sense, even whilst experiencing an epistemic attention deficit. Consider the loud student in the over-crowded classroom who dominates the teacher's time to the detriment of others through loud and disruptive behaviour. In one sense, this student demands and takes up more attention than he is due. The teacher may spend a large proportion of her time asking the student to be quiet, attempting to coerce him into joining in with group work, intervening in his attempts to distract other students. But unless this attention involves taking the student seriously as an epistemic agent and is focused on the student's agential epistemic contribution, this would not represent an epistemic attention excess. ${ }^{5}$

\footnotetext{
${ }^{3}$ Note that someone may be taken seriously as an epistemic agent even if they are not owed credibility and / or epistemic attention within a given context. Those who lie or deliberately mislead, for example, such as online trolls, may need to be taken seriously as malicious epistemic agents in order to be effectively combatted. But they may well lose their right to epistemic attention within online contexts as a result of showing themselves to be irresponsible or malicious epistemic agents. While we cannot fully address the issue of how to manage epistemically malicious agents here, one way to minimise epistemic attention in practice, at least in relation to experts, would be to sanction those who deliberately lie and mislead by placing them on a register of 'epistemic polluters' (Ryan 2018). Note that this approach would take these polluters seriously as epistemic agents, albeit ones that have violated the epistemic standards of the community and who are being punished as a result. We thank an anonymous reviewer for giving us the opportunity to clarify this point.

${ }^{4} \mathrm{Cf}$. Ture and Hamilton (1992: 4) on the difference between individual racism and institutional racism.

${ }^{5}$ There are ways in which a person might experience some other form of epistemic credibility excess, and these may involve some form of harmful excess epistemic attention. Ella Whiteley (forthcoming), for example, describes 'harmful salience perspectives', in which certain aspects of a person's identity are paid undue excess attention (in favour of other more meaningful aspects). This may well become a demand for unreasonable excess epistemic contributions as a 'representative' of a given marginalised identity, in a form of epistemic exploitation (Berenstain 2016) or as a spokesperson or token instance of the marginalised group (Davis 2016).
} 
Further, if the student is viewed as a problem, rather than as an epistemic agent in his own right, he may also be on the receiving end of an epistemic attention deficit. ${ }^{6}$ We may find the teacher's treatment of the student understandable, but it may nevertheless be epistemically harmful or unjust. ${ }^{7}$

\subsection{Epistemic Attention Deficits, Beliefs, Agenda-Setting and Common Ground}

We will discuss in $\S 3$ below what it might mean to say that someone is 'owed' epistemic attention, but for now we just need to be clear that an epistemic attention deficit involves some party being deprived of something which matters. Access to due epistemic attention is relevant in practical matters. The starting point for our argument of the harm of epistemic attention deficits is that attention has an important role to play in influencing people's beliefs and in influencing what they take to be epistemically, politically or socially relevant. Given this, someone who is the subject of an epistemic attention deficit will be less able to influence what other people believe, or take to be epistemically, politically or socially relevant, than they would be able to do if they were not subject to this deficit (all else being equal). Affected individuals have a restricted ability to (i) influence people's beliefs, to (ii) set the agenda and to (iii) help establish the shared common ground.

The first and most straightforward way in which an attention deficit leads to a lack of epistemic influence is through the impact on being able to influence what people believe. As Archer et al. (2020) argue, the amount of attention paid to someone has an important impact on their ability to influence what other people believe, in a way that is not reducible to credibility. In order for our testimony to have any influence on what people believe it needs to first be paid attention to. It does not matter how credible people would find our testimony if they do not pay that testimony any attention. In addition, the larger the platform someone has, the more attention they are likely to be paid. This in turn gives them an opportunity to have their testimony heard. This may not directly impact their credibility but it will increase that person's ability to influence what people believe by enabling them to reach a larger number of those people who would be disposed to believe what they have to say.

The second way in which attention plays a role in determining people's ability to exert epistemic influence is through agenda setting (Archer et al. 2020). The concept of agenda setting was developed by McCombs and Shaw (1972) to explain the power of the media in shaping which issues are deemed to be of political importance. By deciding what stories to cover, how to cover them and the prominence to give to this coverage, the media have the ability to influence what issues are seen as important and to what degree to a far greater extent than ordinary individuals do. As Bernard Cohen (1963) points out, the media are often more influential in determining what issues people attend to than in determining peoples' actual opinions on those issues. Whom the media direct our attention to therefore determines what counts as relevant for even forming an opinion at all.

\footnotetext{
${ }^{6}$ We consider instances in the classroom later in this paper in $\S 3$.

${ }^{7}$ Identifying a distinction between injustice and harm is difficult and subject to competing conceptual and practical definitions. We take the simplified position that an epistemic attention deficit is, by definition, unjust, only in the sense that it is less than a person is owed in some sense. We do not take it that what someone is owed must directly relate to some named source against whom one has a particular claim and can apportion blame. Rather, one is owed what other agents who do not experience epistemic attention deficit(s) ought to be / would be granted under similar circumstances.
} 
Finally, and relatedly, we can think of agenda-setting as the establishment of the 'rhetorical space' (Code 1995) or 'common ground' of shared presuppositions which make up the, "mutually accepted background information" of communicative exchange (Stanley 2002: 322), or of shared social and political existence. Individuals may disagree with respect to the veracity of certain items within that common ground, and the common ground may contain falsehoods, political myths (Bottici 2007), implicit prejudices, and even intentional propaganda (Stanley 2015), but if it is widely believed to be 'known', or can be used without widespread conscious questioning of its veracity, an item forms a part of our mutually-shared common understanding. Understood in this way, the importance of agenda-setting is clear: those who set the agenda determine both what counts as knowledge and the social and political spheres in which we operate. ${ }^{8}$ Someone who is the subject of an epistemic attention deficit has a reduced ability to impact the common ground within which all epistemic agents operate. ${ }^{9}$ When we offer undue attention to the perspectives of some and provide a lack of attention to the perspectives, concerns and interests of others, the common ground naturally shifts. When powerful media agents allocate attention and engage in agenda-setting, this effectively determines what the common ground of discourse is (E.g., Basu 2018; Moore and Ramsay 2017).

We have defined epistemic attention deficits as involving a lack of something that one ought otherwise to have. We will say more about what this means in terms of epistemic agency in \$3.3. Before doing so, however, we should say a bit more about the explicit primary and secondary harms of epistemic attention deficits: how are epistemic attention deficits harmful?

\section{The Primary, Secondary, and Tertiary Harms of Epistemic Attention Deficits}

We have argued that epistemic attention matters in the communicative and social sphere. Those who lack epistemic attention have a reduced ability to (i) influence others' beliefs, to (ii) set the agenda and to (iii) help establish the shared common ground. These are claims about the material impact of a lack of epistemic attention (whether this is as a result of a deficit or otherwise). Now, however, we want to provide a more substantive explanation of the primary harm of epistemic attention deficits, in and of itself, and of the secondary and tertiary harms which accompany them.

\footnotetext{
${ }^{8}$ We might also think of this in terms of an Overton window: the range of ideas tolerated in public discourse. We cannot step too far outside of the window in political or social discourse without being perceived as saying the unthinkable. We prefer to think in terms of a shared common ground as it is not only that assertion $\mathrm{P}$ is deemed to be unacceptable. It is that assertion $\mathrm{P}$ cannot be identified, expressed or communicated. Note that Dotson raises similar ideas when she discusses the challenge of undertaking academic philosophy beyond the very real, yet constructed, metaphilosophically-constructed edges of analytic philosophy (Dotson 2019).

${ }^{9}$ We discuss the common ground as a monolith here, but of course, there may be multiple (and competing) sets of common ground amongst and within distinct communities. Here, we are interested in problems with the common ground(s) relevant to the context in which a given individual is attempting to be recognised as an epistemic agent. The relevant common ground is therefore the dominant one in which a person seeks to be given epistemic attention.
} 


\subsection{Epistemic Agency and the Primary Harm of Epistemic Attention Deficits}

We cache out the primary harm of epistemic attention deficits in terms of epistemic agency and moral status.

The primary harm of epistemic attention deficits occurs when some party is paid less epistemic attention than they are owed. Some party is deprived of something which they ought to have. As such, these deficits constitute a pro tanto harm. Targets of epistemic attention deficits are not provided with due attention. When this involves failing to afford attention to an individual's voice or specific contributions this is an epistemic harm. But what makes epistemic attention due? An epistemic attention deficit may target an entire group of individuals - the harm may be perpetuated against all those who share feature $\mathrm{X}$ or who belong to association Y etc. - but, we contend, the primary harm of epistemic attention deficits can only be experienced by the agential members of that group. ${ }^{10}$ Epistemic attention is something which is owed (to varying levels and degrees within different domains and contexts) to epistemic agents.

Being an epistemic agent entails being one who has the ability to know, with some degree of accuracy, capability, and credibility. There are numerous ways of interpreting the link between epistemic agency and moral status: as, for example, it being a prerequisite for entering the moral sphere of reciprocal recognition between persons (e.g., Congdon 2018); as it being a substantive part of being a moral agent (e.g., Elgin 2013); or as it being important in avoiding (epistemic) objectification (e.g., Fricker 2007; Pohlhaus 2014). Regardless of how we cash this out, being treated as an epistemic agent is in some way important to our ethical status: an individual who is harmed in her capacity as an epistemic agent, is harmed in a morally significant way.

When epistemic attention deficits affect our ability to contribute to the shared common ground of knowledge and beliefs, we are restricted in an essential component of being an epistemic agent. It is important for individual epistemic agents to be able to participate in the establishment of the shared common ground of knowledge and social interaction. In one sense, "[t]he sharing or pooling of knowledge is a basic epistemic requirement arising from the need to possess enough truths about the world to facilitate survival" (Pohlhaus 2014: 101). Consider, as Fricker does, arguments from the state of nature. Individualistic self-reliance would simply be, "a bad survival strategy", given the significant benefits to having "at one's disposal... the eyes and ears of others too" (Fricker 2007: 110). We do not need an imaginary state of nature, however, to understand that an individual's set of knowledge, beliefs, and opinions, are largely dependent on the knowledge of others. Fluency and range as an epistemic agent therefore depend, in great part, on the knowledge contributions of others.

Our status as epistemic agents depends on our being able to reciprocally contribute to this shared knowledge creation. Epistemic agents are not recognised solely in the specific instances in which they give and accept testimonial assertions. When we fail to provide due epistemic attention to certain individuals or groups we not only miss out on testimonial knowledge or specific contributions to the shared set of common knowledge.

\footnotetext{
${ }^{10}$ More structured collectives, such as corporations, could potentially be the core addressees of epistemic attention deficits if one subscribes to a theory of group agency in which epistemic capability is irreducible to individuals and generates group-level moral duties (e.g., List and Pettit 2011) and in which at least some groups might be suitable candidates to be morally relevant parties within the social sphere (Beer 2004; Smith 2018).
} 
We also deny agential inclusion in the shared process of participating in what counts as relevant information and knowledge. ${ }^{11}$

How much - and what kind of - epistemic attention is any one person or group 'owed'? We do not aim to give a full theory of the level of epistemic attention one is owed in any given situation here. Rather, our claim is only that giving someone less epistemic attention than they are in fact due is an epistemic injustice because of the importance of epistemic attention for epistemic agency and the various harms involved (at primary, secondary and tertiary levels). But note that context will play an important role in determining the level of epistemic attention that someone is due at both the absolute and relative level of epistemic attention. Someone may be deprived of some basic absolute level of attention that they are owed as an epistemic agent within a particular context or domain. For example, given the relevance of their experience, people living in poverty may be owed a certain amount of epistemic attention in media reports about poverty. An absence of this will in itself evince a harm to that group as epistemic agents. However, people may also suffer from a relative deficit of attention. An extensive and well-research media report on poverty may pay sufficient attention to the voices of the poor in some absolute sense: this group may receive the minimum level of attention that a media report on poverty should pay to the voices of those living in poverty. However, this group may still be subject to an epistemic attention deficit if the relative amount of epistemic attention they receive in the report is unjust. For example, if the voices of wealthy people are given far more attention than those of poor people (or indeed, if they feature at all in certain aspects of discussion, such as what it is to experience poverty). In this example, the poor get less attention than they deserve in the relative sense even though they receive what they deserve in the absolute sense. There can then be both relative and absolute attention deficits.

The primary harm of epistemic attention deficits is therefore that one is denied something essential to being an epistemic agent, and that this is a morally relevant concern. Epistemic agency is a morally important concept and epistemic agents are harmed when they are not provided with due epistemic attention. As such, epistemic

\footnotetext{
${ }^{11}$ An anonymous referee points out that given that it is not only the evidence of a person's testimonial reliability that determines the level of epistemic attention that they are due, this opens up the possibility that there may be cases where an epistemic attention deficit may be epistemically permissible (because it is conducive to acquiring true beliefs) but morally impermissible (because it is exclusionary). Consider, for example, the case of a teacher who wants to find out the truth about who freed the class hamster. She takes the word of one known-to-be trustworthy student, rather than surveying all of the witnesses despite them each being qualified and keen to speak. More, she does this in all similar classroom cases, failing to pay due epistemic attention to her other students. It may be that her students were all owed epistemic attention morally (not being known to be particularly dishonest or untrustworthy), but epistemically, the teacher took a reliable route towards truth, making her actions epistemically, if not ethically, permissible. We accept that this is a possibility if one accepts a veritistic account of the goal of epistemic reasoning. Those who accept a broader account of epistemic reasoning may wish to say that excluding someone in this way would also, in fact, be epistemically impermissible. We do not wish to take a stand on which the right view is here, but we do accept that there could be cases where an epistemic attention deficit constitutes a moral wrong but not an epistemic wrong. Although note that the teacher may well be depriving herself of long-term reliable sources of testimony by failing to engage with other students in ways that might benefit her epistemically. The all-things-considered epistemic 'wrongness' verdict for even a purely veritistic account may depend on a full understanding of these long-term risks to truth.
} 
attention deficits are a morally relevant concern. ${ }^{12}$ We are owed epistemic attention as epistemic agents, in relevant contexts, but also, in the general sense to the extent that all other agents are. When epistemic attention deficits affect our ability to contribute to the shared common ground through rendering our experiences less salient or prominent than they ought to be in that shared background then we are, in a very practical sense, restricted in an important aspect of being an epistemic agent.

\subsection{The Secondary Harm of Epistemic Attention Deficits}

The primary harm of epistemic attention deficits might in principle be incurred by any agent, but it will arguably only constitute an epistemic injustice or evidence of epistemic violence when there is evidence that these attention deficits are pervasive, systematic and identity-based against marginalised groups. ${ }^{13}$ However, regardless of whether or not we reserve the terms 'injustice' or 'violence' specifically for these cases of pervasive prejudicial ignorance or not, members of marginalised groups are certainly more likely to find themselves the victims of systematic epistemic harm through epistemic attention deficits precisely because other members of that group also face this deficit. To understand this, we need to consider the related

\footnotetext{
${ }^{12}$ It is worth emphasising that this account of epistemic attention deficits as a harm to epistemic agency can be contrasted with other meta-accounts of what the importance of epistemic agency actually consists of, such as ones grounded in recognition theory (e.g., Honneth 1995, 2001; Ikäheimo and Laitinen 2007). More recent recognition theory literature has sought to explicate ways in which epistemic injustice or a lack of epistemic respect (Giladi and McMillan 2018) may be understood as problems or failures of recognition, in response to McConkey's (2004) initial challenge to consider this, as well as expanding on what expressive epistemic recognition might require (e.g., Congdon 2018). However, epistemic attention deficits remain importantly distinct from recognition failures. First: we can offer epistemic recognition and still fail to pay due epistemic attention. We may fully recognise the agential and personhood status of, for example, people living in poverty as persons, and we may make expressive gestures to articulate and demonstrate this. But we may still fail to afford them due epistemic attention within a given contrastive context (in not seeking out their knowledge in relevant policy-making domains, for example). This might be because we fail to recognise them as moral or epistemic agents against some absolute baseline, thus fundamentally misrecognising them, but it might also simply be that we believe that other agents - experts, academic researchers, politicians etc. - have more, or sufficient, insight into a given set of policy requirements than do ordinary citizens. Further, in recognising that epistemic attention deficits may be structurally caused, rather than individually-motivated or directed, it may be entirely possible that a person can be treated with the respect and recognition due to her as a person, whilst structural factors ensure that she fails to be provided with due epistemic attention. Consider the case we have considered elsewhere, for example, of the teacher in a classroom in which working class students fail to ask questions when stuck, while middle-class students do ask questions. Here, the teacher may fully recognise the working class student under conditions of equal respect and meaningfully express a clear interest in hearing from all students equally and a desire to help them all equally, yet the student may still fail to receive due epistemic attention because of preexisting structural factors which have taught her not to ask questions (Calarco 2014). Providing due epistemic attention would require doing more than recognising the student as a person. It might require active changes to the background conditions which have led to the student being unwilling to ask for help in these settings, or teachers going out of their way to ask more directly targeted questions of working-class students to allow them to feel able to ask for help. And second: paying epistemic attention to an epistemic agent may be one way to perform expressive epistemic recognition, but it may not be sufficient for doing so. Congdon's account in which specifically epistemic recognition requires epistemic love, respect and esteem, for example, requires a great deal more than only epistemic attention in relevant contexts (Congdon 2018). We can, therefore, pay due epistemic attention and yet fail to offer epistemic recognition of the kind that confers a status of full epistemic agency as these recognitive meta-approaches conceive of it.

${ }^{13}$ Dotson, for example, proposes that we ought to understand epistemic violence in testimonial cases as taking place when the ignorance which causes it is "pernicious and harmful" (Dotson 2011: 238): a direction-of-fit which is very likely to apply to individuals who share an identity which is systematically prejudicially marginalised.
} 
secondary harm of epistemic attention deficits. The secondary harm of epistemic attention deficits consists in their impact on an agent's ability to participate in numerous common and valuable epistemic practices that others are able to participate in, all else being equal. There are both direct and indirect impacts on the individual epistemic agent who is also a member of a more generally marginalised group.

First, the direct impact. In contrast with the 'informational perspective' on testimonial exchange, the participant perspective recognises that "discussion, inquiry, deliberation [...] asking questions, floating ideas, considering alternative possibilities, and so on", are also all a vital part of epistemic inquiry and shared knowledge creation (Hookway 2010: 155-156). At the individual level, those facing epistemic attention deficits are denied the opportunity to participate in common and valuable epistemic inquiry due to their primary lack of recognition as epistemic agents within a given domain or context, leading to a range of secondary specific interactional epistemic harms of this participatory nature. Individuals are not only harmed in their ability to contribute knowledge and information, but also in their ability to participate in epistemic inquiry. At the individual level of interaction this is problematic: those facing epistemic attention deficits lack the opportunity to influence others' beliefs or to directly influence the take-up of their knowledge and opinions.

Second, there is an indirect and more pervasive harm to individuals who experience epistemic attention deficits and who are members of more generally marginalised groups. Pervasive epistemic attention deficits - as experienced by members of marginalised groups mean that the agent is systematically blocked or hindered in contributing knowledge and opinion to the set of common knowledge, as outlined in $\$ 3.1$ above. As a result, topics which are salient to one's own identity and interests may not be discussed and acted on in the wider community at all (or may be done so in harmful ways). Further, one cannot easily contribute to broader topics which are of value, and which have impact to one's own life, politically and socially. Individuals are restricted in their ability to set the political and social agenda and influence a shared common ground for discussion and debate.

This harm is likely to be further magnified because those who would set the agenda in one's disfavour have a greater proportional impact than they ought to. Recall that, according to our working definition, attention is contrastive. When the voices of marginalised people are ignored, this is often accompanied by paying greater proportional attention to the voices or inputs of others. As Crawford suggests: "Attention is a resource - a person has only so much of it" (Crawford 2015). As might be indicated by our discussion in $\$ 3.1$ above, this does not mean that the pursuit of epistemic attention is a zero-sum game. The clearest reason for this is that it is not the only form of attention available. Paying someone epistemic attention may come at the cost of paying a different kind of attention to something else, rather than at the cost of paying epistemic attention to a different person. For example, reading a book in a park may involve paying epistemic attention to the author rather than attending to the beauty of the trees swaying in the wind. Nevertheless, it will often be the case that the victims of epistemic attention deficits have a reduced proportional contribution to the common ground of beliefs and knowledge. The sum total negative impact on individual contributions to the common ground is therefore greater than the sum of its parts. It is further magnified when this harm is multiplied across all or most individual members of a marginalised group. The risk in terms of agenda-setting is, therefore, not only that one cannot influence the agenda, but that those who would set the agenda in one's disfavour have a greater proportional impact than they ought to. If that agenda comes to contain negative views with regard to one's group then one becomes more likely to face further attention deficits (in addition to other material harms). 
The result is that members of marginalised groups are likely to find themselves the victims of systematic epistemic attention deficits precisely because other members of that group also face this problem, in a vicious circle of proportionally greater epistemic attention exclusion. And this restricted epistemic impact makes continued epistemic attention deficits more likely, resulting in an increased likelihood of systematic injustice, in which earlier unjust treatment makes further unjust treatment more likely.

\subsection{The Tertiary Harms of Epistemic Attention Deficits}

Finally, there are of course multiple further tertiary harms which may accompany epistemic attention deficits, particularly as enacted against marginalised groups within a cycle of harm. These tertiary harms may be both epistemic and material.

In epistemic terms, a lack of attention paid to working-class children, for example, harms educational performance (Calarco 2011, 2014; Reay 2017):

As working-class people [...] regularly pointed out, they often felt overlooked and disregarded in schooling, part of an anonymous backdrop that middle-class children can shine against (Reay 2017: 138).

This is an epistemic attention deficit, as it is a failure to give working-class children the attention which they are due as people with epistemic capacities that can be acknowledged, celebrated, and (most importantly in this context) developed.

This is compounded when their perceived lack of ability leads them to be overrepresented in the lower performance sets and given even less epistemic attention as a result. In the words of, Shulah a working-class child cited in Reay's study of the educational disadvantages of working-class children:

The behaviour gets worse in the bottom set when, like, teachers don't pay attention to you. And they pay attention to, like, the higher ability students and, like, you get bored because there's nothing to do if you don't understand the work. (cited in Reay 2017: 78).

Here the lack of epistemic attention paid to working-class children in education has a clear detrimental impact on their educational performance.

Again, epistemic attention deficits may be relative or absolute in this context. Someone may be deprived of some basic absolute level of attention that they are owed as an epistemic agent. For example, in an underfunded school system all of the pupils may not receive the level of epistemic attention that they deserve from their teachers due to large class sizes. But people may also suffer from a relative deficit of attention. In a very well-funded school system, it may be the case that all students receive more epistemic attention than the basic level that any child may be due. Nevertheless, epistemic attention deficits may still be present in such a school, if one group of pupils, for instance working-class pupils, are systematically given less attention than another group. In this example, the working-class pupils get less epistemic attention than they are due in the relative sense even though they receive more than they are due in the absolute sense. ${ }^{14}$

It is worth noting that the attention deficits facing the economically disadvantaged are not restricted to education. As a study into the representation of poverty in the UK media found,

\footnotetext{
$\overline{14}$ This could also be understood in terms of there being different baselines for measuring epistemic attention deficits under well-funded and non-well-funded background conditions.
} 
poor people are often not paid attention to in the UK media, even in reports specifically about poverty. In the words of the report:

People experiencing poverty featured in fewer than one in eight UK 'poverty reports' in the UK news (13 per cent). It is much more common that the only source of information is the journalist writing the article (or presenting the broadcast) and it is more common for data to be used to describe poverty (20 per cent) than people's experiences (13 per cent). (McKendrick et al. 2008: 23).

Those living in poverty do not receive epistemic attention with regard to reporting on their own situation, which as the authors of the report point out, plays a role in shaping the public's view of those in poverty. This in turn, has a negative impact on poor people's ability to change their material circumstances.

Similarly, Patricia Hill Collins (2000) has argued that the lack of attention paid to black women's thought has had a crucial role to play in maintaining their oppression. According to Collins, the result of ignoring the contributions of a group of oppressed people is that it allows the powerful to maintain their position of power. In her words: "Suppressing the knowledge produced by any oppressed group makes it easier for dominant groups to rule because the seeming absence of dissent suggests that subordinate groups willingly collaborate in their own victimization." (Collins 2000: 3).

Epistemic attention deficits also carry further tertiary risks to an individual's epistemic agency, beyond the primary harm of the deficit in itself which we discuss in $\S 3.1$ above. This further tertiary harm is that one may become a different kind of epistemic agent and have one's epistemic agency altered altogether: in a situation where certain kinds of epistemic agents are paid more epistemic attention to than others, there is an incentive to become more like the kinds of epistemic agent who will be paid attention to.

To see this more clearly let's return to the example of the educational disadvantages facing working-class children in education. According to a study by Calarco (2011) of elementary school children in the United States, one reason why working-class children receive less attention from their teachers is that they are less likely to ask for their help than middle-class children. The willingness to ask for help and the ability to do so effectively is a form of cultural capital that middle-class children are likely to be equipped with when they start school and that working-class children are likely to lack. This is problematic, as teachers expect children to be willing and able to ask for help when they need it. In a later study, Calarco (2014) found that one reason for this difference is that working-class parents coach children to defer to teachers, while middle-class parents coach children to negotiate for teacher assistance. In this example, the kind of agency the children display in class plays a role in determining the amount of epistemic attention they receive from their teachers. However, the kind of agency that is effective in gaining teachers' attention is also playing a role in shaping the kind of agency children are encouraged to embody. This means that the kind of agency that is being paid attention to influences the kinds of agent children are being encouraged to become. ${ }^{15}$ This is deeply concerning.

Further, this is not the end to the risk of epistemic agential harms from epistemic attention deficits. In $\S 4$ below we identify that epistemic attention deficits also create fertile ground for

\footnotetext{
${ }^{15}$ We wish to emphasize that we do not mean to suggest that working-class parents should respond to this situation by adopting the coaching strategies of middle-class parents. A proper response to this situation should not place the burden on working-class parents to adapt to middle-class norms.
} 
both testimonial and hermeneutical injustices to flourish, affecting the long-term ongoing individual agential powers to contribute for those who are members of epistemically marginalised groups.

\section{Epistemic Attention Deficits and Other Forms of Epistemic Injustice}

We have argued that attention deficits constitute both a primary and secondary epistemic harm, in and of themselves and may lead to additional non-epistemic tertiary harms. However, they will also often be linked to other forms of specifically epistemic harm in important ways. We have already touched on participatory epistemic injustices. Here are some further ways in which one form of epistemic harm impacts, causes and / or stems from another.

First, epistemic attention deficits may be caused and causally implicated in ongoing cycles of testimonial harm. Testimonial injustice, for example, takes place when testifiers are not given due credibility in testimonial exchange (Fricker 2007). These credibility deficits are not in themselves epistemic attention deficits. As Pohlhaus identifies, we can only downgrade the testimony of those that we recognise - however poorly - as epistemic subjects or agents in the first place (Pohlhaus 2014). Without due epistemic attention, the credibility deficit could not have occurred in the first place. However, when individuals are denied appropriate credibility for their testimony, as in the case of testimonial injustice (Fricker 2007: 28) for example, future epistemic attention deficits are likely: we do not pay attention to those we have in the past taken to be non-credible and whose testimony we have not relied upon in any meaningful way.

Dotson's discussion of testimonial quieting bears some similarity to Fricker's analysis of testimonial injustice, but here, the testimonial harm is conceptualized as an oppressive practice leading to varying situational harms (Dotson 2011). Testimonial exchange is attempted but pernicious ignorance prevents the speaker's audience from recognizing the speaker as a knower at all:

the epistemic violence present in such happenings should be located at the juncture where an audience fails to accurately identify the speaker as a knower, thereby failing to communicatively reciprocate in a linguistic exchange due to pernicious ignorance (Dotson 2011: 243).

A person speaks and another hears, but that hearer fails to demonstrate "testimonial competence' in handling the knowledge provided (Dotson 2011: 245). The specific harms which a practice of testimonial quieting might lead to need to be understood on a "case-by-case" basis (Dotson 2011: 239). Again, whilst not an epistemic attention deficit in itself - a speaker and audience are present in some form of interaction, but the audience lacks the competence and / or will to recognise that the speaker is a person with knowledge - many cases of testimonial quieting will make future epistemic attention deficits likely: those viewed as non-knowers during testimony in the past are not likely to be sought out for their knowledge in future.

And epistemic attention deficits may in turn cause pre-emptive forms of testimonial injustice or harm. By failing to provide due epistemic attention we fail to provide opportunities to provide testimony, creating the conditions for pre-emptive testimonial injustice in which speakers are not even considered as potential testifiers or witnesses (Fricker 2007). We also fail to signify that we are capable of taking on board testimony (whether this is intentional or otherwise), leading to practices of self-silencing or testimonial smothering (Dotson 2011). When audiences display this intentional or unintentional unwillingness or inability to offer 
appropriate testimonial uptake, marginalised individuals may coercively pre-emptively selftruncate or smother their testimony (Dotson 2011: 244). Further, we have already identified that epistemic attention deficits against some allow others to have greater proportional epistemic attention within a given context or domain (\$3.2). As a result, those with prejudicial views who do not suffer attention deficits have a greater chance to be heard, cultivating the conditions for harmful testimonial practices on the part of audiences in the first place. And in a viciously circular pattern, those who self-silence in response to this lack of competence or interest on the part of audiences are also then likely to become further removed from the sphere of potential testifiers and experience future epistemic attention deficits: we do not pay attention to those we have become accustomed to not hearing from.

Second, epistemic attention deficits are very likely to cause, and be caused by structurally epistemically harmful practices (Anderson 2012). Hermeneutical injustice takes place when we are unable to generate concepts or to share those concepts (Fricker 2007: 163). Audiences who lack the concepts to recognise both topics (and by implication, marginalised experts on those topics) are unlikely to pay epistemic attention where, and to whom, it ought to be. And reciprocally, attention deficits are themselves likely to lead to individuals being unable to develop the conceptual tools to articulate their experience, or at the very least, to others being able to recognise the conceptual tools of others. Epistemic attention deficits are about determining what exchanges are possible and what it is possible to talk about at all, through restrictions on the common ground (\$3). Without a perceived reason to look for conceptual resources in the areas in which attention has not been paid and in which the shared common ground is impoverished, the potential for hermeneutical injustice is heightened.

\section{Practical Implications}

We have, then, laid out the extensive primary and secondary harms of epistemic attention deficits and identified how they impact on broader epistemic injustices and problems of agency. But how might we respond to this form of epistemic injustice? We cannot fully address this here but will make a few brief remarks.

The obvious initial answer to what to do about epistemic attention deficits is that dominant knowers ought to give due epistemic attention to non-epistemically privileged knowers. Fricker (2007: 90) argues that the virtue of epistemic justice requires hearers to be critically aware of their own identity prejudices to enable them to correct for this when listening to the testimony of others. Hearers should then use this awareness to critically examine how credible they have unconsciously judged a particular speaker to be and, if need be, revise that speaker's credibility upwards to compensate for their prejudice. In the case of epistemic attention deficits, we suggest a similar critical awareness is needed. People need to critically reflect on who they habitually pay attention to and who they are habitually ignoring in the epistemic sphere. This is particularly important for those responsible for directing other people's attention towards certain voices and away from others. Journalists for example, should critically reflect on which voices they are directing people's attention to and which they are ignoring. Similarly, those working in education need to reflect on which voices they are directing their students' attention to by thinking about who makes it onto their syllabus.

However, as we have seen in examining the inter-relation of epistemic attention deficits and other forms of hermeneutical and testimonial harm, and as many have already noted (e.g. Sherman 2016) this is likely to be difficult. Recognising epistemic lacunae and offering 
epistemic attention in structural and individual ways will not be a simple task. In fact, there is good reason to think that the task will be more difficult than that of correcting for credibility deficits. While we are often unaware of the influence of our negative identity prejudices, we can at least train ourselves to look out for situations where we are judging the credibility of people who we are likely to have such prejudices against. This allows us to be on the lookout for cases where we are implicitly making credibility judgements that could be informed by a negative identity prejudice. It seems much harder to do so for epistemic attention deficits: we are mostly unaware that we are failing to pay someone attention. This is an important barrier in the way of such critical reflection.

This is true even though it may well be possible to attempt a general assessment of the kinds of people we tend to pay attention to and attempt to make a special effort to epistemically attend to those we tend to ignore. The journalist Adrienne Lafrance (2016) provides a clear example of this. ${ }^{16}$ In 2013, she analysed her entire year's reporting and found that only $25 \%$ of the people she quoted or mentioned were women. In this way she was able to critically reflect on her patterns of epistemic attention. Rather dispiritingly, though, when Lafrance conducted a similar audit two years later, she received the same results. This shows that altering these patterns of attention is not easy, even for those committed to doing so.

Importantly, then, in order for epistemic attention deficits to be substantively addressed, we suggest that a societal effort needs to be made to change the patterns of epistemic attention. As we have mentioned before, what we pay attention to is greatly influenced by both by the social and cultural context we live in and the context we were brought up in (Zerubavel 2015). These patterns of attention form part of our social practices and will be greatly informed by and partially constitute the dominant ideology in society (cf. Haslanger 2017). A stable political regime will involve patterns of attention that help to stabilise the political order. We can call these dominant and stabilising patterns of attention the attentional regime of a society, and note that these are likely to serve the interests of powerful groups in society. ${ }^{17}$ Trying to address these injustices then, will require altering these entrenched attentional regimes.

There are various ways in which we might attempt to do this. We have already mentioned that journalists, educators and others who work to direct people's attention towards certain voices can seek to direct more attention towards neglected voices. In addition, political organisations and social movements can help to change the dominant patterns of attention. Cultural producers also have an important role to play here and artists, poets, novelists, musicians and filmmakers can help to shift our patterns of attention. More generally, people can seek to provide platforms for those we currently fail to offer epistemic attention to at the individual and structural level.

One approach worth exploring in particular is that of intentionally supporting spokespersons who emerge from amongst the epistemically marginalised to draw attention to important issues which are not specifically related to their marginalised identity. ${ }^{18}$ In supporting

\footnotetext{
${ }_{16}$ Thanks to Mark Alfano for pointing us towards this example.

${ }^{17}$ Our discussion here is influenced by William Reddy's (2001) work on emotional regimes and Alison Jaggar's (1989) work on emotional hegemony.

${ }^{18}$ Note that our concern here is that marginalised individuals are given epistemic attention in relation to important topics of interest and epistemic relevance to those marginalised knowers, and not specifically to the interests of dominant knowers (although they may converge). Due epistemic attention is agency-supporting. Undue epistemic attention, in which a person is expected to act as an epistemic representative for others who share some aspect of that person's (marginalised) identity (Davis 2016), or in which a person is required to provide information purely about their experience of being marginalised (Berenstain 2016) or purely about a topic which interests dominant knowers (Lackey 2020) can be agency-denying in similar ways to those engendered by undue epistemic attention deficits.
} 
spokespersons whose identity usually entails that they are subject to epistemic attention deficits, political and social movements can both draw attention to the important issues at stake and help re-direct epistemic attention. Environmental activist Greta Thunberg, for example, has helped to bring widespread attention not only to climate change but also to children and young people's views on this issue, arguably making the voices of young people more broadly salient: Thunberg's presence in the international media is helping to re-shape the attentional regime with respect to who gets epistemic attention (in this case, young people). Notably, the challenge here is that those we do not pay epistemic attention to are likely to require the support of others in order to gain a sufficient platform to be able to act as a spokesperson. Thunberg's case is the exception rather than the norm, but by intentionally seeking out those who are passionate about a given topic, and who would not normally gain epistemic attention, to be our representatives, it need not be.

A final response worth exploring is that of using already powerful spokespersons to help direct attention where it ought to go. In the absence of widespread structural changes in the generation of knowledge, one answer is that those who are provided with due (or excess) epistemic attention might speak on behalf of those who experience a deficit to draw attention to their experiences. In epistemic attention deficits individuals may receive a lack of due attention as a general participant in knowledge creation or they may receive a lack of attention to their epistemically privileged situational knowledge relating to being a member of a marginalised group. By drawing attention to the latter type of knowledge, lived experience, the more general problem of epistemic attention deficits might, in principle, be alleviated. Topics do not necessarily have to be introduced by those experiencing them in order to impact agendas and agendas, once changed, can reduce epistemic attention deficits. Perhaps epistemically capable others who do have the ability to gain epistemic attention can get epistemically privileged information relating to the situation of marginalised knowers into the common ground and undermine the conditions for future epistemic attention deficits in doing so.

We are however, reticent about widely advocating for this kind of approach. When privileged voices speak on behalf of others the words might not be the ones that they would wish for; the way in which audiences interpret them might itself be affected by perceptions of the speaker; and there is a risk of further epistemic harm. Consider, 'poverty porn'. Here, wellintentioned epistemically powerful authors, charities and media outlets describe the experience of those living in poverty for the consumption by the non-poor ${ }^{19}$ and, increasingly, many are questioning this practice. Beresford (2016), for example, questions the extent to which leftwing media 'misery accounts' of life in poverty impact on either policy or the well-being of UK welfare claimants. Similarly, Michele Wallace expresses related concerns about the attempts of well-intentioned allies speaking up on behalf of black women:

Not only is it impossible to for anybody to speak in anybody else's voice, such a project tends to further consolidate the lethal global presupposition (which is unconscious) in the dominant discourse that women of color are incapable of describing, much less analyzing, reality, themselves, or their place in the world. (Wallace 1990: 251).

In epistemic terms, we suggest that it is likely that hearing such stories from privileged speakers without input from the epistemically marginalised themselves may further epistemically objectify marginalised knowers as things to be talked about rather than to (Fricker 2007:

${ }^{19}$ Consider Welfare Britain - the New Reality (BBC 2013); the Live Aid charity campaign of the 1980s; numerous Oxfam campaigns around the world. 
132). When narratives about the epistemically ignored are not delivered in a way which redirects due epistemic attention, we risk not only reinforcing dominant 'victim' narratives, but also further harm to the epistemic agency of others.

It is important not to place the work of highlighting epistemic attention deficits on those who experience them. The complexity of delivering these messages should not prevent us from attempting to work with marginalised knowers to identify ways to do it, when it is not possible to offer the platform up to those knowers directly. But we should proceed with caution.

\section{Conclusion}

We have argued that attentional deficits, where people are not paid the attention due to them as epistemic agents, constitute distinct form of epistemic injustice. We began by arguing that epistemic attentional deficits affect an agent's ability to influence what others believe and to influence the shared common ground in which testimonial exchanges take place. We then explained the various ways in which epistemic attention deficits harm those who are subject to them. These deficits are harms in and of themselves because they deprive people of an essential component of epistemic agency. They also reduce an agent's ability to participate in valuable epistemic practices. Finally, we argued that epistemic attention deficits both hinder and shape the development of epistemic agency. We finished by exploring some practical implications arising from our discussion.

Our focus has been on showing the need to accept that epistemic attentional deficits constitute a distinct and harmful form of epistemic injustice. This paves the way for future work in this area to investigate in more detail the nature of these harms and the various situations in which they are likely to occur and groups they are likely to affect. An important topic for future work to investigate is that of new forms of digital media, which profit from controlling and monitoring our attention. Future work could also seek to demarcate more precisely than we have room for here what constitutes specifically epistemic attention, and whether there are parallels in the pattern we identify here and what one is owed in other spheres, such as phenomenological and perceptual attention. Our hope is that further research might also develop more specific strategies to enable individuals and collectives to combat these injustices by altering their patterns of attention. Such strategies are badly needed if we are to address the injustices faced by those who are unseen, overlooked and ignored. ${ }^{20}$

Open Access This article is licensed under a Creative Commons Attribution 4.0 International License, which permits use, sharing, adaptation, distribution and reproduction in any medium or format, as long as you give appropriate credit to the original author(s) and the source, provide a link to the Creative Commons licence, and indicate if changes were made. The images or other third party material in this article are included in the article's Creative Commons licence, unless indicated otherwise in a credit line to the material. If material is not included

\footnotetext{
${ }^{20}$ The authors would like to thank audiences at the 2019 SWIP-UK conference on Epistemic Injustice, Reasons and Agency at the University of Kent, organised by Lubomira Radoilska as part of a joint project with Veli Mitova, and at the 2019 OZSW Moral Psychology and Technology Graduate Course at Delft University. Special thanks are also owed to Mark Alfano, Jon Bebb, Rob Compaijen and Benjamin Matheson for detailed comments on drafts of this paper. Leonie Smith would also like to thank the Tilburg center for Moral Philosophy, Epistemology and Philosophy of Science and their generous provision of a Visiting Fellowship in 2018 during which this work was co-conceived and developed with Alfred Archer.Alfred Archer's work was supported by the NWO (The Netherlands Organisation for Scientific Research) Grant Number 016.Veni.174.104.
} 
in the article's Creative Commons licence and your intended use is not permitted by statutory regulation or exceeds the permitted use, you will need to obtain permission directly from the copyright holder. To view a copy of this licence, visit http://creativecommons.org/licenses/by/4.0/.

\section{References}

Anderson E (2012) Epistemic justice as a virtue of social institutions. Soc Epistemol 26(2):163-173

Archer A, Cawston A, Matheson B, Geuskens M (2020) Celebrity, democracy, and epistemic power. Perspectives on Politics 18(1):27-42

Ballantyne N (2019) Epistemic trespassing. Mind 128(510):367-395

Basu L (2018) Media amnesia: rewriting the economic crisis. Pluto Press, London

Beer C (2004) Do stakeholders have intrinsic moral rights? Bus Ethics Eur Rev 13(1):65-70

Berenstain N (2016) Epistemic exploitation. Ergo 3(22):569-590

Beresford P (2016) Presenting welfare reform: poverty porn, telling sad stories or achieving change? Disab Soc 31(3):421-425

Boduroglu A, Shah P, Nisbett RE (2009) Cultural differences in allocation of attention in visual information processing. J Cross-Cult Psychol 40(3):349-360

Bottici C (2007) A Philosophy of Political Myth, Cambridge University Press, Cambridge.

Broadbent D (1958) Perception and communication. Pergamon Press, New York

Bueno CC (2016) The attention economy: labour, time and power in cognitive capitalism. Rowman \& Littlefield International, London

Calarco JM (2011) “I need help!” social class and children's help-seeking in elementary school. Am Sociol Rev 76(6):862-882

Calarco JM (2014) Coached for the classroom: parents' cultural transmission and children's reproduction of educational inequalities. Am Sociol Rev 79(5):1015-1037

Code L (1995) Rhetorical spaces: essays on gendered locations. Routledge, London and New York

Cohen BC (1963) The press and foreign policy. Princeton University Press, Princeton, NJ

Collins PH (2000) Black Feminist Thought: Knowledge, Consciousness and the Politics of Empowerment, Routledge, New York and London.

Congdon M (2018) "Knower" as an ethical concept: from epistemic agency to mutual recognition. Fem Phil Quart 4(4):1-26

Crawford M (2015) The Cost of Paying Attention. The new York Times. https://www.nytimes.com/2015/03/08 /opinion/sunday/the-cost-of-paying-attention.html. Accessed 21 February 2020.

Crerar C (2016) Taboo, hermeneutical injustice, and expressively free environments. Episteme 13(2):195-207. https://doi.org/10.1017/epi.2015.35

Davis E (2016) Typecasts, tokens, and spokespersons: a case for credibility excess as testimonial injustice hypatia 31 (3): 485-501

Davis E (2018) On epistemic appropriation. Ethics 128(4):702-727

Doran P (2017) A political economy of attention, mindfulness and consumerism: reclaiming the mindful commons. Routledge, London

Dotson K (2011) Tracking epistemic violence, tracking practices of silencing. Hypatia 26(2):236-257

Dotson K (2019) Tales from an apostate. Philos Issues 29:69-83

Elgin C (2013) Epistemic agency. Theory Res Educ 11(2):135-152

Fricker M (2007) Epistemic injustice: the power and ethics of knowing. Oxford University Press, Oxford

Fricker M (2012) Silence and institutional prejudice. In: Crasnow SL, Superson AM (eds) Out from the shadows: analytical feminist contributions to traditional philosophy. Oxford University Press, Oxford, pp 387-304

Giladi P, McMillan N (2018) Introduction: epistemic injustice and recognition theory. Fem Philos Q 4(4):1-4

Haslanger S (2017) Racism, ideology, and social movements. Res Philos 94(1):1-22

Honneth A (1995) The struggle for recognition: the moral grammar of social conflicts. Translated by Anderson J, MIT Press, Cambridge

Honneth A (2001) Invisibility: on the epistemology of 'recognition'. Aristot Soc Suppl Vol 75(1):111-126

Hookway C (2010) Some varieties of epistemic injustice: reflections on Fricker. Episteme 7(2):151-163

Ikäheimo H, Laitinen A (2007) Analyzing recognition: identification, acknowledgement, and recognitive attitudes towards persons. In: Van den brink B, Owen D (eds) Recognition and power: Axel Honneth and the tradition of critical social theory. Cambridge University Press, Cambridge, pp 33-56

Jaggar AM (1989) Love and knowledge: emotion in feminist epistemology. Inquiry 32(2):151-176

James W (1890/ 1981) The principles of psychology, Harvard University Press, Cambridge

Lackey J (2020) False confessions and testimonial injustice. J Crim Law Criminol 110(1):43-68 
Lafrance A (2016) I analysed a year of my reporting for gender Bias (again). The Atlantic https://www. theatlantic.com/technology/archive/2016/02/gender-diversity-journalism/463023/. Accessed 21 Feb 2020

Lanham RA (2006) The economics of attention: style and substance in the age of information. University of Chicago Press, Chicago

List C, Pettit P (2011) Group agency: the possibility, design, and status of corporate agents. Oxford University Press, Oxford

MacFayden G (2018) Memory, language and silence: barriers to refuge. J Immigr Refug Stud 17(2):168-184

Masuda T, Nisbett RE (2001) Attending holistically versus analytically: comparing the context sensitivity of Japanese and Americans. J Pers Soc Psychol 81:922-934. https://doi.org/10.1037/0022-3514.81.5.922

McCombs ME, Shaw DL (1972) The agenda-setting function of mass media. Public Opin Q 36(2):176-187

McConkey J (2004) Knowledge and acknowledgement: 'epistemic injustice' as a problem of recognition. Politics 24(3):198-205

McKendrick JH, Sinclair S, Irwin A, O’Donnell H, Scott G, Dobbie L (2008) The media, poverty and public opinion in the UK. Joseph Rowntree Foundation, York

Medina J (2011) The relevance of credibility excess in a proportional view of epistemic injustice: differential epistemic authority and the social imaginary. Soc Epistemol 25(1):15-35

Moore M, Ramsay G (2017) Acrimonious and divisive: the role the media played in Brexit. LSE blogs. https://blogs.lse.ac.uk/brexit/2017/05/16/acrimonious-and-divisive-the-role-the-media-played-in-brexit/. Accessed 1 June 2019

Pohlhaus G Jr (2012) Relational knowing and epistemic injustice: toward a theory of willful hermeneutical ignorance. Hypatia 27(4):715-735

Pohlhaus G Jr (2014) Discerning the primary epistemic harm in cases of testimonial injustice. Soc Epistemol 28(2):99-114

Prinz J (2005) A Neurofunctional theory of consciousness. In: Brook A, Akins K (eds) Cognition and the brain: the philosophy and neuroscience movement. Cambridge University Press, Cambridge, New York, pp 381396

Prinz J (2011) Is attention necessary and sufficient for consciousness? In: Mole C, Smithies D, Wu W (eds) Attention: philosophical and psychological essays. Oxford University Press, New York, pp 174-203

Reay D (2017) Miseducation: inequality, education and the working classes. Policy Press, Bristol

Reddy WM (2001) The navigation of feeling: a framework for the history of emotions. Cambridge University Press, Cambridge

Ryan S (2018) Epistemic Environmentalism. J Philos Res 43:97-112

Sherman BR (2016) There's no (testimonial) justice: why pursuit of a virtue is not the solution to epistemic injustice. Soc Epistemol 30(3):229-250

Smith L (2018) The curious case of Ronald McDonald's claim to rights: an ontological account of differences in group and individual person rights. Journal of Social Ontology 4(1):1-28

Stanley J (2002) Modality and what is said. Nous 36(16):321-344

Stanley J (2015) How propaganda works. Princeton University Press, Princeton

Ture K (Carmichael S), Hamilton CV (1992) Black power: the politics of liberation. Vintage, New York

Wallace M (1990 [2016]) Invisibility blues from pop to theory. Verso Books, London

Watzl S (2017) Structuring mind: the nature of attention and how it shapes consciousness. Oxford University Press, Oxford

Whiteley E (forthcoming) Harmful salience perspectives. In: Archer S (ed) Salience: a philosophical inquiry. Routledge, Abingdon, Oxon

$\mathrm{Wu}$ W (2014) Attention. Routledge, London

Wu T (2017) The attention merchants: the epic scramble to get inside our heads. Vintage, New York

Zerubavel E (2015) Hidden in plain sight: the social structure of irrelevance. Oxford University Press, Oxford

Publisher's Note Springer Nature remains neutral with regard to jurisdictional claims in published maps and institutional affiliations. 